\title{
CHARACTERIZATION OF ENALAPRIL AND RANITIDINE CHLORINATION BY-PRODUCTS BY LIQUID CHROMATOGRAPHY/HIGH-RESOLUTION MASS SPECTROMETRY AND THEIR TOXICITY EVALUATION
}

\author{
Frederico Jehár Oliveira Quintão\#, Mariana Pierotti de Souza", Silvana de Queiroz Silva", Sérgio Francisco Aquino" and \\ Robson José de Cássia Franco Afonso*,\#
}

Escola de Minas, Universidade Federal de Ouro Preto, 35400-000 Ouro Preto - MG, Brasil

Recebido em 07/12/2016; aceito em 09/03/2017; publicado na web em 09/06/2017

\begin{abstract}
Due to its low cost, its capability for disinfection and oxidation, chlorination using gaseous chlorine or hypochlorite salts, has also been commonly applied in water treatment plants for oxidation and disinfection purposes. Little is known about the identity and toxicity of by-products resulting from the chlorination of pharmaceutical micropollutants, such as enalapril (ENA) and ranitidine (RAN). ENA and RAN chlorination by-products were characterized in this study by high-performance liquid chromatography coupled to high-resolution mass spectrometry (HPLC/HRMS) and their toxicity were assessed by MTT assay. Chlorination experiments with ENA and RAN solutions ( $10 \mathrm{mg} \mathrm{L}^{-1}$ ) indicate degradation efficiencies of $100 \%$ for both compounds after only 5 min of exposure to chlorine at concentration of $9.53 \mathrm{mg} \mathrm{Cl}_{2} \mathrm{~L}^{-1}$. On the other hand mineralization rates were lower than $3 \%$, thereby indicating there was accumulation of degradation by-products in all experiments. Mass spectrometric analysis revealed, at all times of reaction after the addition of hypochlorite, the presence of 1-(2-((4-(chlorophenyl)-1-ethoxy-1-oxobutan-2-yl)amino)propanoyl)pyrrolidine-2-carboxylic acid (enalapril by-product) and N-chloro-N-(2-(((chloro-5-((dimethylamino)methyl)furan-2-yl)methyl)sulfinyl)ethyl)-N-methyl-2nitroethene 1,1-diamine (ranitidine by-product). Despite the formation of oxidized chlorinated by-products in all chlorination assays, the treated solutions were nontoxic to HepG2 cells by the MTT assay. It has been observed that chlorination (10 $\left.\mathrm{mg} \mathrm{L}^{-1}, 5 \mathrm{~min}\right)$ of ENA and RAN solutions exhibited high degradation efficiencies of the target compounds and low mineralization rates. Based on the mass spectrometry data, the routes for ENA and RAN successive oxidation by chlorine has been proposed.
\end{abstract}

Keywords: enalapril; ranitidine; high-resolution mass spectrometry; disinfection by-products; MTT assay.

\section{INTRODUCTION}

A variety of pharmaceutical compounds have been found in different environmental compartments. ${ }^{1}$ Such compounds are found into the environment due to their resulting incomplete metabolism in human or animal bodies, and their discharge in raw or partially treated sewage, as well as improper disposal of pharmaceutical industry effluents or solid waste leachates. The presence of pharmaceuticals in water bodies raises concerns on environmental quality and human health. ${ }^{2}$ The presence of certain pharmaceuticals in drinking water also indicates that conventional water treatment is not completely adequate to remove them. ${ }^{2,3}$

Pharmaceutical compounds can be found in low concentrations in surface waters, however their effects on aquatic ecosystems are already acknowledged. ${ }^{4-6}$ On the other hand, the effects of pharmaceuticals on human health are still controversial and mainly dependent on their therapeutical classes. Special concern is devoted to antibiotics due to their ability to induce bacterial resistance. Nevertheless, the influence of chronic exposure to complex mixtures of low concentrations of pharmaceuticals and its disinfection byproducts is unpredictable, since there might be synergist effects that are not easily taken into account. ${ }^{7,8}$

Among the pharmaceutical groups, anti-hypertensive drugs have also received special attention due to their wide application in human therapy. Enalapril (ENA) is used in the treatment of hypertension and some types of chronic heart failure. Recent reports by the World Health Organization (WHO) state that high blood pressure is the primary or secondary cause of $50 \%$ of all cardiovascular diseases worldwide, thereby evidencing a high consumption of hypertensive

*e-mail: robsonjcfafonso@gmail.com

\#Programa de Pós-Graduação em Engenharia Ambiental (ProAmb) drugs. Enalapril was found at $35 \mathrm{ng} \mathrm{L}^{-1}$ in the influent and $0.85 \mathrm{ng} \mathrm{L}^{-1}$ in the effluent of a sewage treatment plant (STP) in Nevada, USA. ${ }^{9}$

Ranitidine (RAN) is a histamine antagonist H2-receptor. This compound has been classified as a drug of high environmental concern because it occurs in a variety of aquatic environments. For example, a median value of $288.2 \mu \mathrm{g} \mathrm{L}^{-1}$ was measured in the effluents of several STPs in Italy. ${ }^{10}$

Due to its low cost, good disinfection and oxidation capacity, chlorine $\left(\mathrm{Cl}_{2}\right)$, usually dosed in the forms of gaseous chlorine or hypochlorite $\left(\mathrm{OCl}^{-}\right)$solutions, has been commonly applied in water treatment plants. Chlorine can be used to induce a primary disinfection at the beginning of the treatment (pre-oxidation), and/or to maintain a residual chlorine in the distribution system (post-treatment). Despite its advantages, chlorine can lead to the formation of halogenated organic compounds, mainly from natural organic matter, some of which exhibit the potentially carcinogenic activity, ${ }^{11}$ and little is known about the formation and toxicity of disinfection byproducts from chlorination of water containing pharmaceutical compounds.

ENA and RAN are generally well tolerated, however cases of acute hepatotoxicity in patients treated with these drugs are reported. ${ }^{12-15}$ A study undertaken, with the crustacean test species Thamnocephalus platyurus, to determine the effect levels of 28 selected pharmaceuticals indicates that enalapril has low toxicity up to the concentration of $200 \mathrm{mg} \mathrm{L}^{-1} .{ }^{16}$ The literature reported the half maximal effective concentration $\left(\mathrm{EC}_{50}\right)$ of $374 \mathrm{mg} \mathrm{L}^{-1}$ and $\mathrm{EC}_{50}$ of $650 \mathrm{mg} \mathrm{L}^{-1}$ of RAN for $P$. putida and Daphnia magna respectively. ${ }^{17}$

The MTT (3-(4,5-dimethylthiazol-2-yl)-2,5-diphenyltetrazolium bromide) tetrazolium reduction assay is a sensitive, quantitative, and reliable colorimetric assay that measures viability of cells. ${ }^{18,19}$ Human hepatoma HepG2 cells have been intensively used for MTT assay for toxicity and genotoxicity evaluation of pure compounds

The present study aims to investigate ENA and RAN degradation, 
in aqueous medium, induced by chlorination using sodium hypochlorite $(\mathrm{NaOCl})$. The concentration of ENA and RAN used in this study was $10 \mathrm{mg} \mathrm{L}^{-1}$. The by-products formed under these oxidative conditions were identified by structural elucidation applying high-performance liquid chromatography coupled to high-resolution mass spectrometry (HPLC/HRMS). The cytotoxicities of the ENA and RAN by-products were evaluated with HepG2 cells MTT assay.

\section{EXPERIMENTS}

\section{Chemicals}

Enalapril and ranitidine were purchased from Sigma Aldrich (Munich, Germany). Their structures, chemical formula and exact molecular mass are shown in Figure 1. Solvents for analytical determinations were acetonitrile (HPLC grade, JT Baker) and ultrapure water Milli-Q system (Milford, MA, USA). Standard solution of sodium hypochlorite at $10 \% \mathrm{w} / \mathrm{v}$ was provided by SEMAE (Municipal Water and Sewage Service) in Ouro Preto, Minas Gerais, Brazil.

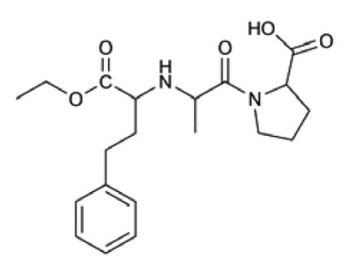

Chemical Formula: $\mathrm{C}_{20} \mathrm{H}_{28} \mathrm{~N}_{2} \mathrm{O}_{5}$ Exact Mass: 376,1998

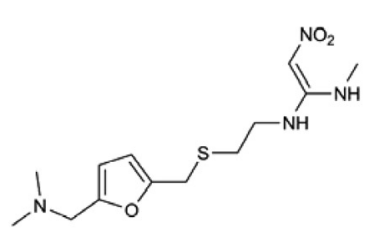

Chemical Formula: $\mathrm{C}_{13} \mathrm{H}_{22} \mathrm{~N}_{4} \mathrm{O}_{3} \mathrm{~S}$ Exact Mass: 314,1413
Figure 1. Chemical structures, chemical formula and exact mass of enalapril and ranitidine respectively

\section{Chlorination experiments}

Chlorination of pharmaceuticals was performed on $20 \mathrm{~mL}$ amber bottles that were maintained in the dark. The stock solutions (100 $\mathrm{mg} \mathrm{L}^{-1}$ ) of ENA and RAN were prepared separately using ultrapure water (Milli-Q) and then $2 \mathrm{~mL}$ of this solution was added to amber bottles so that a final concentration of $10 \mathrm{mg} \mathrm{L}^{-1}$ was obtained. This concentration is much higher than those typically found for ENA and RNA in the environment. However, the concentration of $10 \mathrm{mg} \mathrm{L}^{-1}$ was chosen to facilitate the subsequent analysis, eliminating the steps of extraction and pre-concentration of the samples, thereby minimizing errors related to sample preparation. The solutions were stirred for 10 minutes before the degradation tests, which were performed at room temperature (from 22 to $23{ }^{\circ} \mathrm{C}$ ). $2 \mathrm{~mL}$ of sodium hypochlorite stock solution (100 $\left.\mathrm{mg} \mathrm{L}^{-1}\right)$ was then added to the flasks to achieve a final concentration of $10 \mathrm{mg} \mathrm{L}^{-1}$. After the desired contact time $(0,5,10$, 15 and 30 minutes), samples were collected and sodium thiosulfate ( $2 \mathrm{~mL}$ at $100 \mathrm{mg} \mathrm{L}^{-1}$ ) was added to neutralize the remaining sodium hypochlorite and to stop the chlorination reactions. The chlorination was accomplished over a period of 30 minutes and all samples were collected and stored in amber glass bottles.

The aliquots collected from the chlorination tests were also maintained under identical conditions (stored at $4{ }^{\circ} \mathrm{C}$ ) until the moment of Total Organic Carbon (TOC) and mass spectrometry analyses.

\section{TOC Analyses}

TOC analyses were carried out using a TOC analyzer (Shimadzu, model TOC-L, Kyoto, Japan) which employs the $680^{\circ} \mathrm{C}$ combustion catalytic oxidation method and NDIR detection, thereby providings an wide range of concentration (up to $30,000 \mu \mathrm{g} \mathrm{L}^{-1}$ ) with a limit of detection estimated as $4 \mu \mathrm{g}$ TOC $\mathrm{L}^{-1}{ }^{20,21}$

\section{Direct infusion high resolution mass spectrometry}

The direct infusion analyses were carried out in a high resolution mass spectrometer (IT-TOF; Shimadzu Corporation, Kyoto, Japan), hybrid ion trap and time of flight, equipped with an electrospray ionization source operating in positive mode $(+4.5 \mathrm{kV})$. The interface and CDL (curved dessolvation line) were operated at constant temperature $\left(200^{\circ} \mathrm{C}\right)$. The nebulizer and drying gas $\left(\mathrm{N}_{2}\right)$ at a constant flow rate of $1.5 \mathrm{~L} \mathrm{~min}^{-1}$ and $15 \mathrm{~L} \mathrm{~min}^{-1}$, respectively. An accurate mass-to-charge $(\mathrm{m} / \mathrm{z})$ range of 100-600 was recorded after the samples were directly introduced into the ESI source by injecting $15 \mu \mathrm{L}$ at a flow rate of $0.2 \mathrm{~mL} \mathrm{~min}^{-1}$ of acetonitrile with $0.1 \%$ of formic acid. ${ }^{21}$

\section{Liquid chromatography coupled to mass spectrometry}

The evolution, formation and degradation of each by-product during the chlorination processes, was monitored by high performance liquid chromatography coupled to a hybrid mass spectrometry system. The liquid phase chromatograph was equipped with a binary pump (Nexera LC-30AD; Shimadzu Corporation, Kyoto, Japan) and the autosampler (SIL 30AC; Shimadzu Corporation, Kyoto, Japan) was interfaced to a hybrid ion trap and time of flight mass spectrometer (IT-TOF; Shimadzu Corporation, Kyoto, Japan) duly equipped with an electrospray ionization source operating in positive mode $(+4.5 \mathrm{kV})$. The LC separations were performed using a Nucleosil ${ }^{\circledR} 100-5 \mathrm{CN}$ column ( $250 \mathrm{~mm} \times 4.6 \mathrm{~mm} \times 5 \mu \mathrm{m}$ particle diameter) under a flow rate of $1.0 \mathrm{~mL} \mathrm{~min}^{-1}$. The mobile phase used was water (A) and acetonitrile (B), both containing $0.1 \%$ formic acid. A gradient was used so that the percentage of organic solvente (B) was changed linearly as follows: $0 \mathrm{~min}, 30 \%$; $16 \mathrm{~min}, 90 \%$; $22 \mathrm{~min}, 30 \%$; $27 \mathrm{~min}, 30 \%$. The separations were completed within $27 \mathrm{~min}$. The column eluent was split, so that the flow became $0.2 \mathrm{~mL} \mathrm{~min}^{-1}$ prior to entering the electrospray capillary at the mass spectrometer. The interface and CDL (curved dessolvation line) were operated at a constant temperature of $200{ }^{\circ} \mathrm{C}$. The nebulizer and drying gas $\left(\mathrm{N}_{2}\right)$ at a constant flow rate of $1.5 \mathrm{~L} \mathrm{~min}^{-1}$ and $15 \mathrm{~L} \mathrm{~min}^{-1}$, respectively. The accurate mass-to-charge $(\mathrm{m} / \mathrm{z}$ ) range of 100-600 was recorded.

\section{Cytotoxicity assay (MTT)}

MTT assay is widely used for assessment of cytotoxicity, cell viability, and proliferation studies in cell biology. MTT gives a yellowish aqueous solution which, on reduction by dehydrogenases and reducing agents present in metabolically active cells, yields a water insoluble violet-blue formazan. The lipid soluble formazan product may be extracted with organic solvents and estimated by absorption spectrophotometry. It is currently widely thought that the amount of MTT formazan is directly proportional to the number of living cells..$^{22,23}$

The cytotoxicity of ENA and RAN and its transformation products were determined with 3-(4,5- dimethylthiazol-2-yl)-2,5diphenyltetrazolium bromide (MTT) assay according to Zegura et al. ${ }^{19}$ and Mosmann. ${ }^{23}$ HepG2 cell monolayers were trypsinized, washed with culture medium, plated in 96-well flat-bottomed plates $\left(4 \times 10^{4}\right.$ cells per well) and incubated in a humidified atmosphere with $5 \% \mathrm{CO}_{2}$ at $37{ }^{\circ} \mathrm{C}$. After $24 \mathrm{~h}$ incubation, serial dilutions of the ENA and RAN samples (0.01, 0.25, 0.50, 0.75 and $\left.1.00 \mathrm{mg} \mathrm{L}^{-1}\right)$ made in phosphate buffered saline (PBS) were added to appropriate wells, and the plates properly incubated for additional $20 \mathrm{~h}$. After 
this time, the supernatants were removed from the wells, and MTT ( $28 \mu \mathrm{l}$ of a $5 \mathrm{mg} \mathrm{mL}^{-1}$ solution in PBS) was added to each well; the plates were incubated for $90 \mathrm{~min}$ at $37^{\circ} \mathrm{C}$; then DMSO $(130 \mu \mathrm{L})$ was added to each well to dissolve the formazan crystals. After shaking the plates to ensure complete dissolution of formazan, the optical density was determined at $490 \mathrm{~nm}$ in a multiwell spectrophotometer (Spectra max340PC - Molecular Devices). Cell survival (viability) was determined by comparing the absorbance of the wells containing the cells treated with MTF solutions (treated and untreated) with the cells exposed to a negative control (culture media with cells). A positive control was run in parallel by using pure DMSO. An initial solution of sodium hypochlorite $1 \mathrm{mg} \mathrm{L}^{-1}$ was neutralized by sodium thiosulfate and used as blank. A $30 \%$ reduction in the viability of a given sample was considered as a positive cytotoxic response..$^{19,23}$ These experiments were also performed in triplicate.

\section{RESULTS AND DISCUSSION}

\section{Degradation and mineralization}

The chlorination using $\mathrm{NaOCl}$ promoted the removal of ENA and RAN with high efficiencies, and both were completely degraded after 5 minutes of reaction. In spite of these impressive degradation rates, the TOC data (Figure 2) revealed that ENA and RAN were not mineralized to a similar extent, even after a treatment time as long as $30 \mathrm{~min}$. Moreover, the mineralization rates derived from chlorination of both pharmaceuticals were negligible, estimated in only $3 \%$. These findings indicate that chlorine addition changed the original ENA and RAN molecules to produce recalcitrant by-products which could not be completely degraded under the oxidative conditions employed.

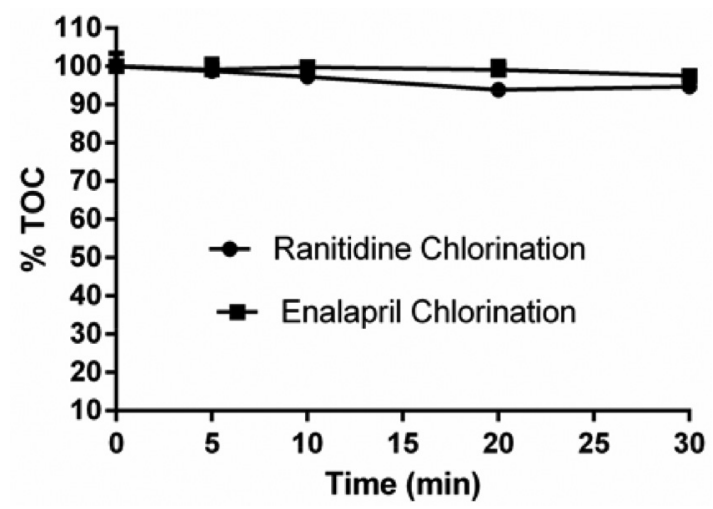

Figure 2. Total organic carbon content (\%TOC) as a function of reaction times for chlorination of ENA and RAN solutions. (Reaction conditions : Chlorine concentration: $9.53 \mathrm{mg} \mathrm{L}^{-1}$; RAN and ENA initial concentrations: $10 \mathrm{mg} \mathrm{L}^{-1}$

Three types of reactions can occur between $\mathrm{NaOCl}$ and a given organic compound depending on its structure: oxidation; addition of chlorine to unsaturated bonds; and electrophilic substitution of chlorine at nucleophilic sites. ${ }^{11,24,25}$ Electrophilic substitution reactions are particularly common with chlorine, where chlorine, replaces a hydrogen atom on activated aromatic ring. Reaction with amines to form chloramines is also common, along with oxidation reactions that do not form halogenated products. ${ }^{25,26}$ For both ENA and RAN, It can be observed the occurrence of chlorinated by-products in the samples treated with $\mathrm{NaOCl}$ (Figure 3).

\section{Identification of ENA and RAN by-products}

The aliquots collected during the degradation experiments were first analyzed by direct infusion HRMS. A representative mass spectra determined from the aliquots collected from the chlorination is displayed in Figure 3. The observation of additional ions that were detected in the mass spectra and extracted-ion chromatograms (Figure 4) of the reaction aliquots is most likely related to the formation of by-products over the course of the reaction. The basic drugs ENA and RAN readily reacted with hypochlorite in pure water so that after 5 min of chlorination, both pharmaceuticals were completely transformed into their major products.

The reaction of ENA with $\mathrm{NaOCl}$ leads to substitution of one hydrogen atom of the aromatic ring by a chlorine atom, thereby forming a monochlorinated ENA (Figure 3a). It has been reported in the literature that some pharmaceuticals containing aromatic ring react with sodium hypochlorite via electrophilic substitution. One example is given for the lipid-regulator gemfibrozil which react with chlorine via electrophilic substitution to produce chlorinated derivatives (i.e. 4 -chloro-gemfibrozil and 4,6-dichlorogemfibrozil). ${ }^{27}$ This information corroborates the data obtained for enalapril.

On its turn, chlorination of ranitidine led to the accumulation of one by-product, following the formation of sulfoxide and substitution of two hydrogen atoms by chlorine, one in the amine group and the other in the furan ring (Figure $3 b$ ). ${ }^{28}$ The antidepressant, fluoxetine, which also contains an amino group in its structure, can react rapidly with chlorine to produce N-chlorofluoxetine. On its turn, the antiinflammatory diclofenac reacts with chlorine to form the following major products: chloro-diclofenac. These degradation by-products result from an initial electrophilic attack of chlorine on the aromatic ring or amine group. ${ }^{21,26,27}$ Therefore the data obtained for ranitidine, corroborate with the results reported in the literature.

The chlorination of ENA and RAN was studied in ultrapure water, and the results obtained using HPLC/HRMS detection are shown in Figure 4. The chromatogram shown in Figure 4a refers to ENA solution before any contact with hypochlorite and after $30 \mathrm{~min}$ of contact. In its turn, the chromatogram shown in Figure $4 \mathrm{~b}$ presents a RAN before contact with hypochlorite and after chlorination for $30 \mathrm{~min}$. The chromatographic separation of by-products in their protonated and sodium adducts can be seen in the selected ion chromatograms. For all four compounds, the retention time shifted immediately after chlorine addition. The peak corresponding to the parent compound was completely transformed to the new peak when an excess of free chlorine was added.

After a meticulous analysis of these data, and isotopic ratio of by-products (Figure 5), it was possible to propose the molecular formulae for all by-products detected in the ENA and RAN chlorinated samples, all allegedly detected in their protonated forms, as shown in Figure 6.

The mechanism for ENA chlorination (Figure 6a) is proposed to start with the attack of its aromatic ring by the positively polarized chlorine atom of hypochlorite ion $\left(\mathrm{OCl}^{-}\right)$, thereby forming a monochlorinated carbocation. This intermediate may be rearranged through the elimination of one hydrogen atom to form monochlorinated-ENA. Similar substitution mechanism of a hydrogen atom by hydroxyl at the ENA aromatic ring by plasma destruction was described by Magureanu and co-authors. ${ }^{29}$

Figure $6 \mathrm{~b}$ shows the formation of the chlorinated by-product of RAN which is typically rapid and depends on the amine basicity. This by-product was formed through the substitution of two hydrogen atoms by chlorine, one of amine group and the other from the furan ring, with the formation of sulfoxide group. Vargas and co-authors realated the formation of sulfoxide from simultaneous oxidation of $\mathrm{S}$ atom of ranitidine using electrochemical advanced oxidation. ${ }^{30} \mathrm{~A}$ study of the oxidation of ranitidine in which $6.7 \mathrm{mg} \mathrm{L}^{-1} \mathrm{Cl}_{2}$ gaseous also shows the formation of chloramines similar to that formed in this study. ${ }^{31}$ 
a)
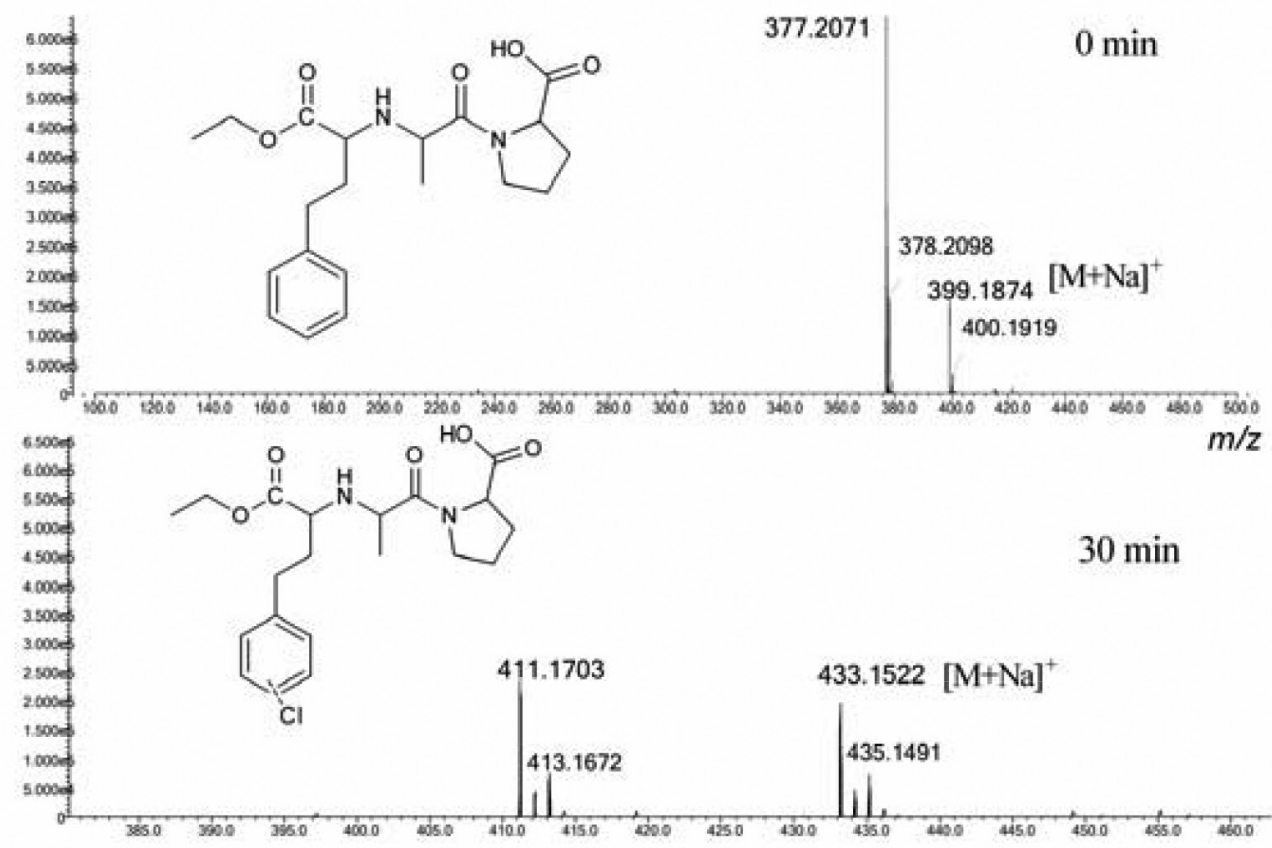

b)
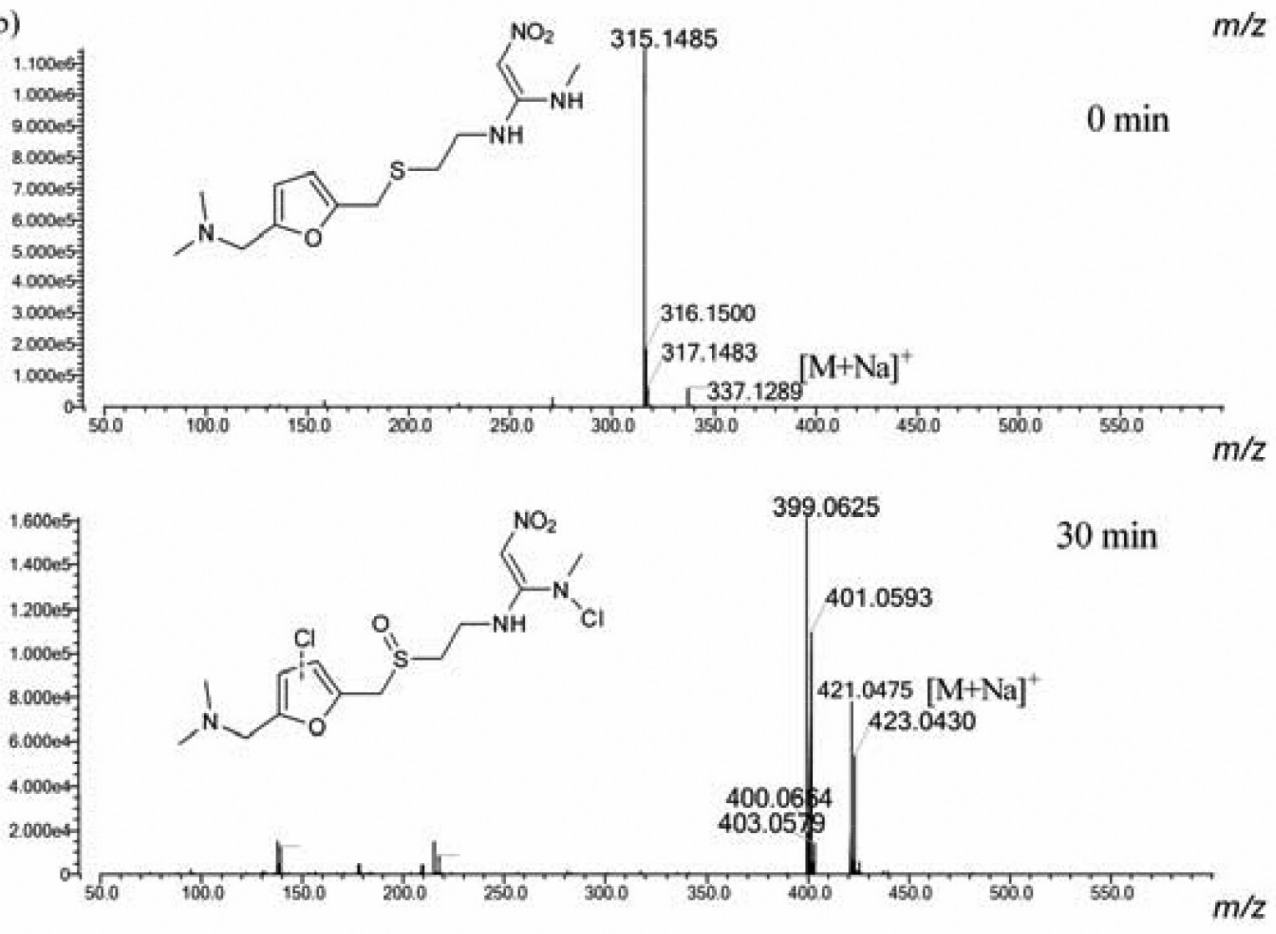

Figure 3. High resolution mass spectra (HRMS) of (a) enalapril and (b) ranitidine obtained with ESI $^{+}$recorded for aliquots ( 0 and 30 min) of chlorination

\section{Citotoxicity assay (MTT)}

There is little toxicological information on pharmaceuticals chlorinated by-products. ${ }^{32}$ Especially the ENA and RAN transformation products, therefore their cititoxity were evaluated, by means of MTT assay. This assay uses MTT (3-[4,5-dimethylthiazol2-yl]-2,5-diphenyltetrazolium bromide) which is a water soluble tetrazolium salt, that is converted to an insoluble purple formazan by cleavage of the tetrazolium ring by succinate dehydrogenase present within the mitochondria. The formazan produced is impermeable to the cell membranes and therefore it accumulates in healthy cells. Figure 7 shows cell viability data for undiluted (at the highest tested concentration, i.e., $1 \mathrm{mg} \mathrm{L}^{-1}$ ) of ENA and RAN toxicity experiments. It shows the viability when the cells were treated with samples generated during chlorination of these pharmaceuticals solutions. Viability of cells exposed to all solutions (raw and treated) was the same as that of control cells. It has to be noted that in order to avoid overestimation or underestimation of the toxicity of a substance, incubations with various concentrations were required to be able to accurately determine the cytotoxicity. Considering a 30\% reduction in cell viability as cytotoxic effect, ${ }^{19}$ none of the diluted samples tested decreased cell viability. These results indicates that there was no decrease in cell viability after their exposition to ENA, RAN or their degradation by-products. Therefore, one can deduce that none 
a)

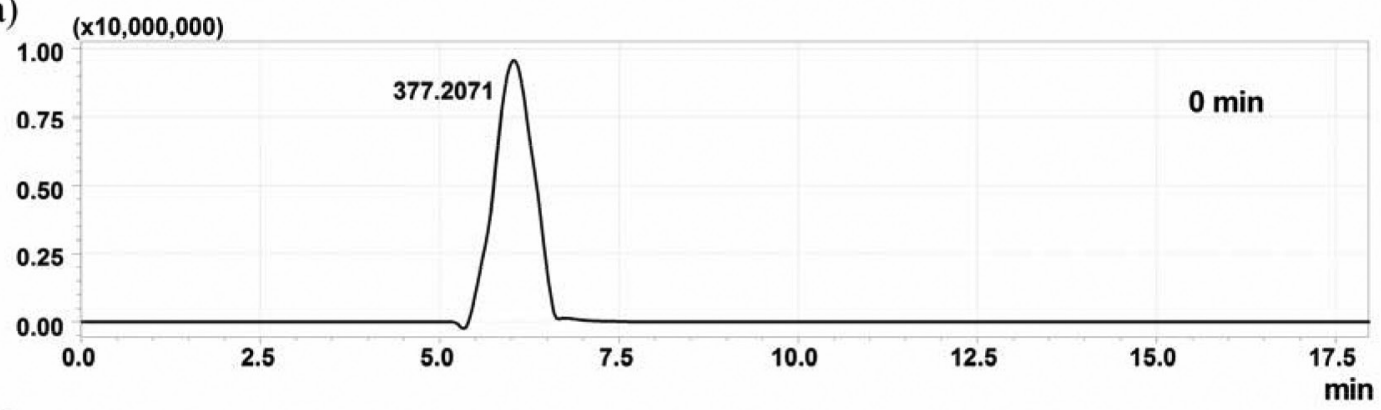

b) $\quad(\times 10,000,000)$

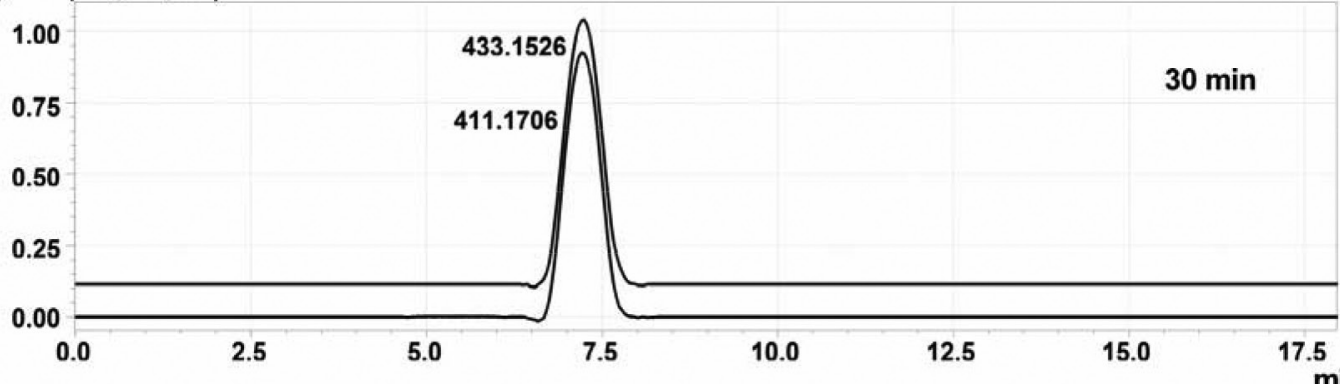

c)

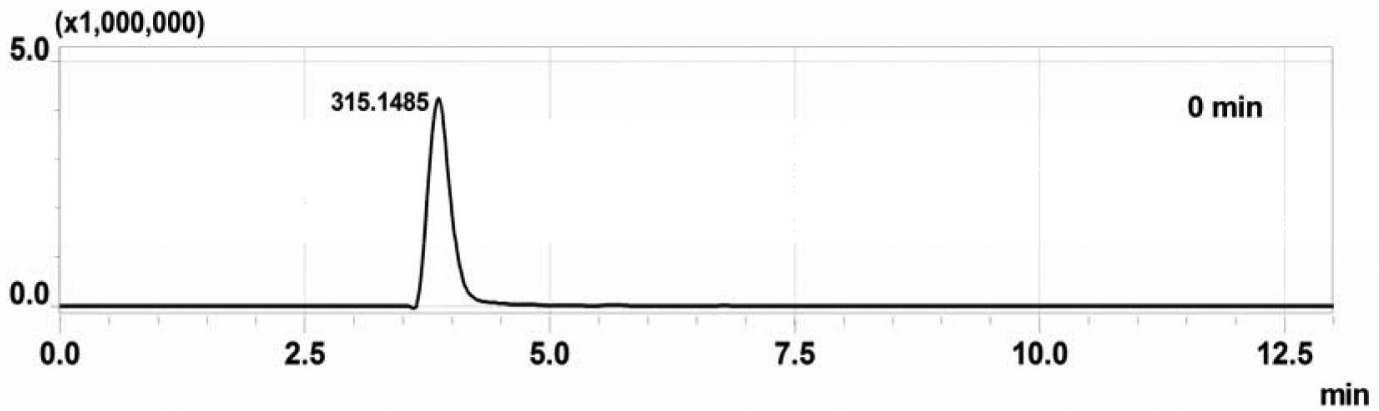

d)

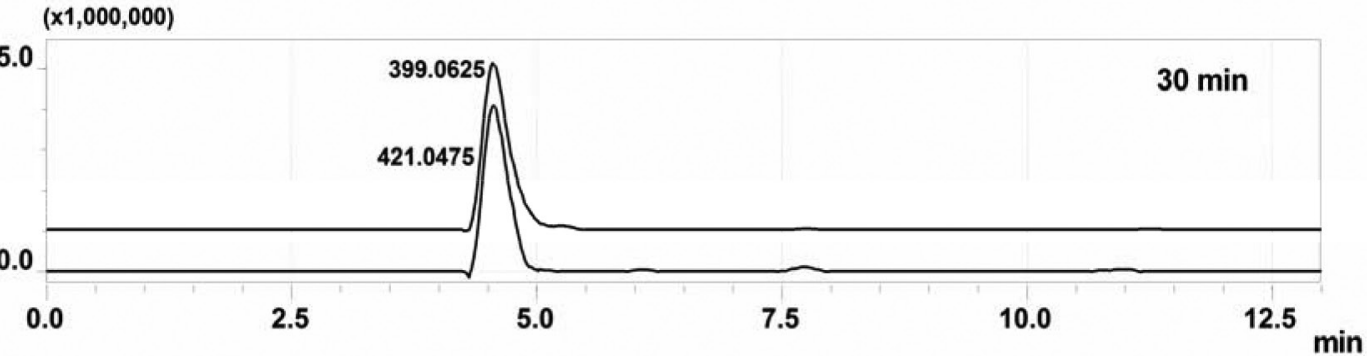

Figure 4. Extracted-ion chromatogram (EIC) using a mass window of $\pm 3.00 \mathrm{mDa}$ from a) enalapril ; b) by-products of enalapril chlorination ; c) ranitidine and d) by-products of ranitidine chlorination

of the samples tested was toxic to HepG2 cells. It is also observed that the ENA and RAN reduced cell viability in a higher percentage than the samples collected after the chlorine treatment. This indicates that the chlorinated by-products were less toxic than the precursor compounds under the MTT assay used conditions.

\section{CONCLUSION}

Enalapril and ranitidine are pharmaceuticals that have shown to be prone to react with hypochlorite in water matrix. After 5 min of chlorination, both pharmaceuticals were completely changed into single 2 major products. The HRMS structural elucidation presented by-products, which are formed via a prompt reaction with hypoclorous acid on the original substrate as well as on the subsequent intermediate compounds. Based on these results a route for the chlorination of ENA and RAN, which comprised of its successive oxidation in the aqueous medium, has been proposed. It can also be concluded that the treated samples containing ENA, RAN and its degradation by-products were not cytotoxic to HepG2 cells as per the MTT assay.

\section{ACKNOWLEDGEMENTS}

The authors wish to thank the Minas Gerais State Science Foundation (FAPEMIG) - process APQ-00918-13; the Brazilian National Research Council (CNPq) - process 473893-2013-1; Coordination for the Improvement of Higher Education Personnel (CAPES) and Federal University Of Ouro Preto (UFOP) for their financial support and the granting of research fellowships. 
a)

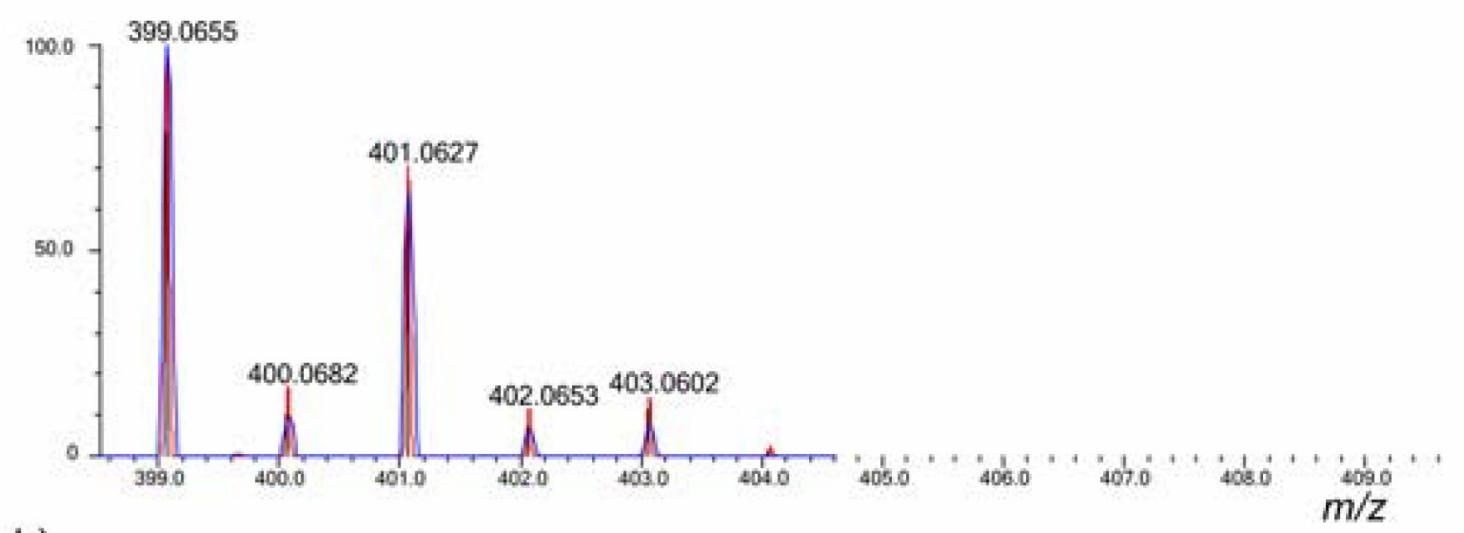

b)

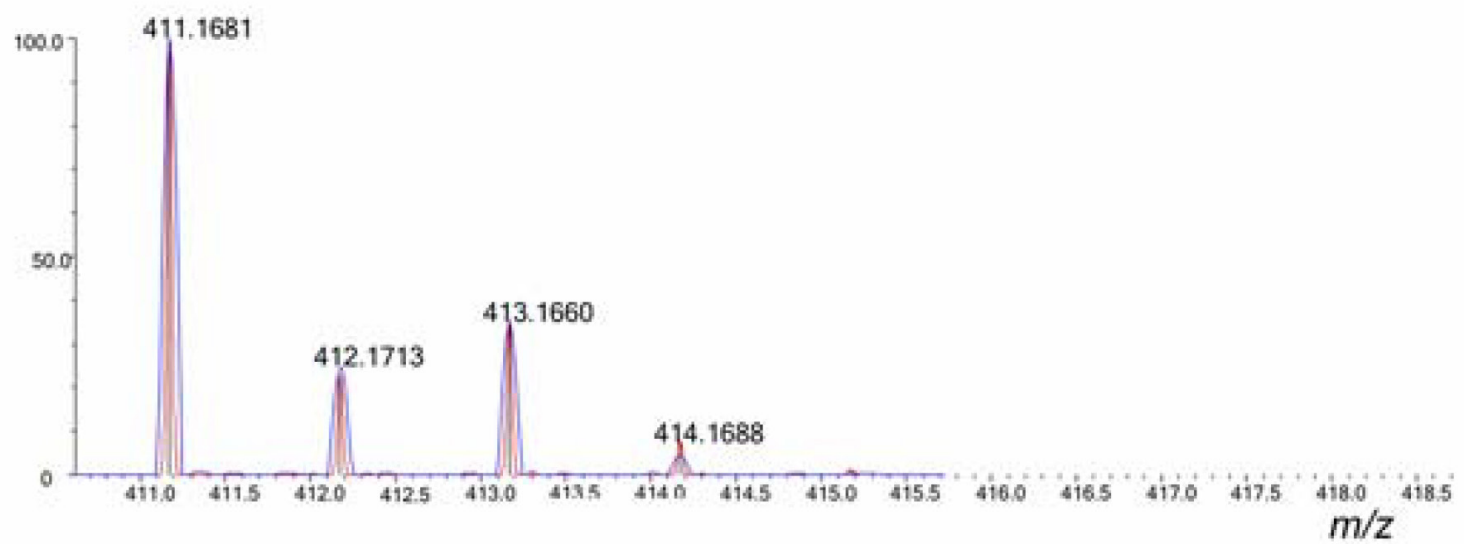

Figure 5. Theoretical (red) and experimental (blue) isotope ratio for the by-products (a) ENA by-product and (b) RAN by-product

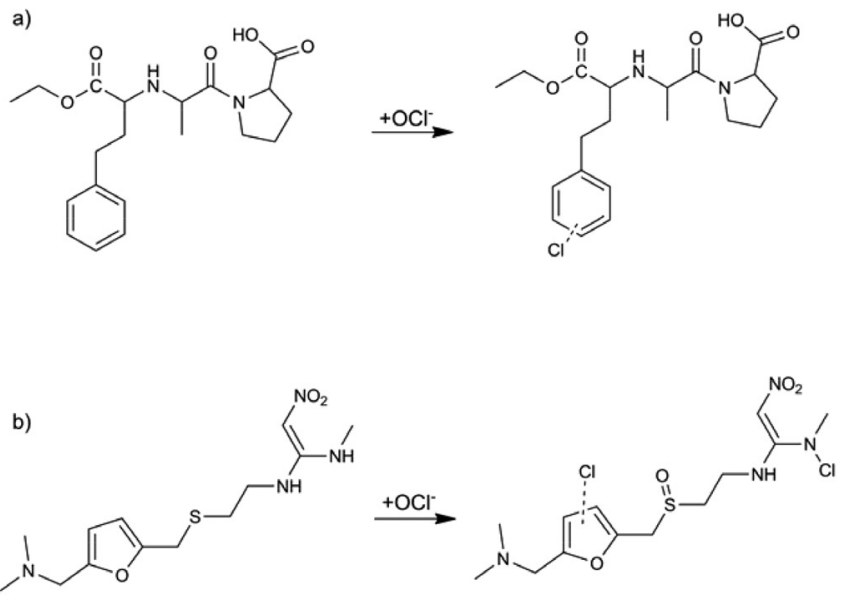

Figure 6. Proposed route for the degradation of (a) enalapril and (b) ranitidine in water with sodium hypochlorite

\section{REFERENCES}

1 Ratola, N.; Cincinelli, A.; Alves, A.; Katsoyiannis, A.; J. Hazard. Mater. 2012, 239-240, 1.

2 Trapido, M.; Epold, I.; Bolobajev, J.; Dulova, N.; Environ. Sci. Pollut. Res. 2014, 21, 12217.

3 Petrie, B. Barden, R. Kasprzyk-Hordern, B.; Water Res. 2015, 72, 3.

4 Halling-Sørensen, B.; Nielsen, S. N.; Lanzky, P. F.; Ingerslev, F.; Lützhøft, H. C. H.; Jørgensen, S. E.; Chemosphere 1998, 36, 357.

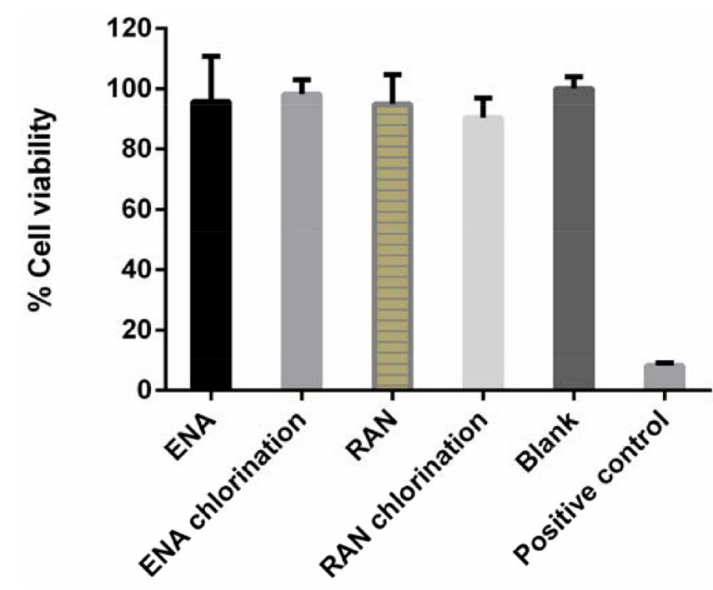

Figure 7. Results of MTT assay of ENA and RAN solutions before (untreated) and after exposure (30 min) with chlorine showing the \% of HepG2 cells viability

5 Jørgensen, S. E.; Halling-Sørensen, B.; Chemosphere 2000, 40, 691.

6 Daughton, C. G.; Ternes, T. A.; Environmental Health Perspectives 1999, 107, 907.

7 Lapworth, D. J.; Baran, N.; Stuart, M. E.; Ward, R. S.; Environ. Pollut. 2012, 163, 287.

8 Liu, J.-L.; Wong, M.-H.; J. Chromatogr. Sci. 2009, 47, 19.

10 Kasprzyk-Hordern, B.; Dinsdale, R. M.; Guwy, A. J.; Water Res. 2008, 42, 3498 . 
11 Acero, J. L.; Benitez, F. J.; Real, F. J.; Roldan, G.; Water Res. 2010, 44, 4158.

12 Todd, P.; Levison, D.; Farthing, M. J.; J. R. Soc. Med. 1990, 83, 271.

13 Rosellini, S. R.; Costa, P. L.; Gaudio, M.; Saragoni, A.; Miglio, F.; Gastroenterology 1989, 97, 810.

14 Fishbein, D. B.; McDade, J. E.; Ann. Intern. Med. 1986, 105, 803.

15 Ramrakhiani, S.; Brunt, E. M.; Bacon, B. R.; Am. J. Gastroenterol. 1998, 93, 822.

16 Nalecz-Jawecki, G.; Persoone, G.; Environ. Sci. Pollut. Res. Int. 2006 $13,22$.

17 Bergheim, M.; Giere, R.; Kummerer, K.; Environ. Sci. Pollut. Res. Int. 2012, 19, 72 .

18 Riss, T. L.; Moravec, R. A.; Niles, A. L.; Duellman, S.; Benink, H. A.; Worzella, T. J.; Minor, L. In Assay Guidance Manual; Sittampalam, G. S.; Coussens, N. P.; Nelson, H.; Arkin, M.; Auld, D.; Austin, C.; Bejcek, B.; Glicksman, M.; Inglese, J.; Iversen, P. W.; Li, Z.; McGee, J.; McManus, O.; Minor, L.; Napper, A.; Peltier, J. M.; Riss, T.; Trask Jr., O. J.; Weidner, J., eds.; Eli Lilly \& Company and the National Center for Advancing Translational Sciences: Bethesda, 2004.

19 Žegura, B.; Heath, E.; Černoša, A.; Filipič, M.; Chemosphere 2009, 75, 1453.

20 da Silva, J. C. C.; Teodoro, J. A. R.; Afonso, R. J. de C. F.; Aquino, S. F.; Augusti, R.; J. Mass Spectrom. 2014, 49, 145.
21 Quintão, F. J.; Freitas, J. R.; Machado, C. de F.; Aquino, S. F.; Silva, S. de Q.; Afonso, R. J. de C. F.; Rapid Commun. Mass Spectrom. 2016.

22 Stockert, J. C.; Blázquez-Castro, A.; Cañete, M.; Horobin, R. W.; Villanueva, Á.; Acta Histochem. 2012, 114, 785.

23 Mosmann, T.; J. Immunol. Methods 1983, 65, 55

24 Armbruster, D.; Happel, O.; Scheurer, M.; Harms, K.; Schmidt, T. C.; Brauch, H. J.; Water Res. 2015, 79, 104.

25 Deborde, M.; von Gunten, U.; Water Res. 2008, 42, 13.

26 Postigo, C.; Richardson, S. D.; J. Hazard. Mater. 2014, 279, 461.

27 Bedner, M. Maccrehan, W. A.; Chemosphere 2006, 65, 2130.

28 Buth, J. M.; Arnold, W. A.; McNeill, K.; Environ. Sci. Technol. 2007, 41, 6228.

29 Magureanu, M.; Dobrin, D.; Mandache, N. B.; Bradu, C.; Medvedovici, A.; Parvulescu, V. I.; Plasma Processes Polym. 2013, 10, 459.

30 Olvera-Vargas, H.; Oturan, N.; Brillas, E.; Buisson, D.; Esposito, G.; Oturan M. A.; Chemosphere 2014, 117, 644.

31 Wang, X.; Yang, H.; Zhou, B.; Wang, X.; Xie, Y.; Water Res. 2015, 87, 403

32 Bond, T., Templeton, M. R.; Graham, N.; J. Hazard. Mater. 2012, $235-236,1$. 